\title{
Efeito da adição de resíduo de rocha ornamental nas propriedades tecnológicas e microestrutura de piso cerâmico vitrificado
}

\section{(Effect of the addition of ornamental rock waste on the technological properties and microstructure of vitrified ceramic floor tiles)}

\author{
A.J.Souza, B. C.A. Pinheiro, J. N. F. Holanda \\ Grupo de Materiais Cerâmicos, LAMAV/CCT, Universidade Estadual do Norte Fluminense Darcy Ribeiro \\ (UENF), Av. Alberto Lamego 2000, Campos dos Goytacazes, RJ 28013-602 \\ ajsouza@uenf.br,bruno@fafic.com.br,holanda@uenf.br
}

\begin{abstract}
Resumo
A indústria de rochas ornamentais gera grandes quantidades de resíduos sólidos na forma de pós finos. Estes resíduos, quando descartados no ambiente, provocam impacto ambiental negativo. Foi feito um estudo sobre a influência de um resíduo de rocha ornamental nas propriedades e microestrutura de piso cerâmico vitrificado. Foi preparada uma série de massas cerâmicas contendo até $30 \%$ em peso de resíduo de rocha ornamental. Peças cerâmicas foram preparadas por prensagem uniaxial e sinterizadas entre 1190 e $1250{ }^{\circ} \mathrm{C}$ em um ciclo de queima rápida. As seguintes propriedades tecnológicas foram determinadas: retração linear, absorção de água, massa específica aparente, e tensão de ruptura a flexão. A evolução da microestrutura e a análise de fases foram acompanhadas por microscopia eletrônica de varredura e difração de raios X. Os resultados mostraram que adições de até $30 \%$ em peso de resíduo de rocha ornamental causaram variações significativas na generalidade das propriedades tecnológicas da massa cerâmica de referência. A microestrutura das peças cerâmicas também foi influenciada com a incorporação do resíduo estudado. Os resultados também mostram que a substituição de feldspato sódico por resíduo de rocha ornamental nas massas cerâmicas tende a melhorar a qualidade do piso cerâmico.

Palavras-chave: resíduo, rocha ornamental, piso cerâmico, microestrutura, propriedades.
\end{abstract}

\begin{abstract}
The ornamental rock industries generate huge amounts of solid wastes (fine powders). These wastes as disposed in the environment generate negative environmental impacts. In this work a study was done on the influence of an ornamental rock waste in the technological properties and microstructure of vitrified floor tile. A series of ceramic pastes were prepared with additions of up to 30 wt \% of waste. Ceramic pieces were prepared by uniaxial pressing and sintered between 1190 and $1250^{\circ} \mathrm{C}$ using a fast-firing cycle. The following technological properties were determined: linear shrinkage, water absorption, apparent density, and flexural strength . The microstructure and phase analysis evolution were accompanied by scanning electron microscopy and X-ray diffraction. The experimental results showed that the addition of up $30 \mathrm{wt} \%$ of WTS caused significant variations in the technological properties of the ceramic paste used as reference. The microstructure of the floor tile pieces also was influenced by the ornamental rock waste added. The results also showed that the replacement of sodic feldspar by ornamental rock waste tends to improve the quality of the vitrified floor tiles.
\end{abstract}

Keywords: waste, ornamental rock, floor tile, microstructure, properties.

\section{INTRODUÇÃO}

Em geral as atividades industriais geram impactos no meio ambiente, que na maioria das vezes são impactos negativos. $\mathrm{Na}$ atualidade o setor produtivo industrial no mundo todo tem se deparado com dois grandes problemas [1]: o uso intensivo de matérias-primas naturais não renováveis, que tendem a se esgotarem em futuro próximo, e produzem cada vez mais resíduos que são descartados no meio ambiente de forma inadequada. A busca de soluções definitivas para estes problemas se constitui em um dos maiores desafios para o setor produtivo no século XX. Em particular o setor de rochas ornamentais está fortemente inserido na problemática ambiental. Isto é decorrente do fato de que este setor é grande gerador de resíduos sólidos, que via de regra são descartados no meio ambiente de forma inadequada, principalmente no Brasil [2,3]. Em geral, esses resíduos são descartados diretamente no solo, sem nenhum tratamento ou previsão de re-utilização. Por outro lado, os órgãos de fiscalização ambiental federal e regional vêm nos últimos anos atuando fortemente na prevenção ambiental. Isto tem levado a uma forte pressão ao setor de rochas ornamentais, para que desenvolvam seus processos produtivos de forma ambientalmente limpa. Isto invariavelmente implica na disposição em aterros sanitários, reciclagem ou re-utilização dos resíduos gerados. 
Os resíduos de rochas ornamentais em forma de lamas após serem submetidos a processo de secagem, são transformados em um material não biodegradável na forma de um resíduo sólido (pó fino). Esses resíduos são ricos em óxidos como $\mathrm{SiO}_{2}, \mathrm{Al}_{2} \mathrm{O}_{3}, \mathrm{~K}_{2} \mathrm{O}, \mathrm{Na}_{2} \mathrm{O}, \mathrm{Fe}_{2} \mathrm{O}_{3}$ e $\mathrm{CaO}$ [4-6]. Estes óxidos são normalmente encontrados nas matériasprimas convencionais utilizadas na fabricação de produtos cerâmicos diversos para construção civil. Portanto, esses resíduos podem servir como uma importante fonte de matéria-prima não convencional de baixo custo para a indústria cerâmica. A indústria de revestimentos cerâmicos brasileira tem apresentado um rápido crescimento nos últimos anos, principalmente em relação à produção de pisos cerâmicos vitrificados de alta qualidade (grês e grês porcelanato). O Brasil é atualmente o terceiro produtor, o segundo consumidor e o quarto exportador mundial de revestimentos cerâmicos [7]. Existe a perspectiva de que em futuro próximo o Brasil será o maior produtor mundial de revestimentos cerâmicos do ocidente, superando Itália e Espanha. Em 2007, a produção nacional de revestimentos cerâmicos foi de 566 milhões $\mathrm{m}^{2}$. As massas cerâmicas triaxiais usadas na fabricação de pisos cerâmicos vitrificados são basicamente constituídas por caulim/material fundente/ quartzo. Em particular, o material fundente na massa cerâmica é muito importante devido a sua capacidade de diminuir a temperatura de formação da fase líquida durante o processo de sinterização. A fase líquida tende a preencher a porosidade aberta da estrutura da peça cerâmica, dependendo de sua viscosidade [8]. Os materiais fundentes naturais mais utilizados são os feldspatos potássico e sódico [9-11]. Dependendo do tipo de piso cerâmico a massa cerâmica pode conter até cerca de $50 \%$ em peso de feldspato. Por outro lado,o crescimento da indústria de revestimento cerâmico brasileira tem resultado no consumo cada vez maior de feldspatos. Isto tem contribuído para o aumento do custo desta importante matéria-prima natural. Esta situação tem levado à busca de materiais fundentes alternativos aos feldspatos, visando a sua substituição parcial ou total nas composições das massas cerâmicas triaxiais. Os resíduos de rochas ornamentais são geralmente ricos em óxidos alcalinos fundentes como $\mathrm{K}_{2} \mathrm{O}$ e $\mathrm{Na}_{2} \mathrm{O}$, dependendo do tipo de rocha ornamental processada. Isto torna esses resíduos uma excelente alternativa para substituir o material fundente natural em composições cerâmicas para pisos vitrificados [4-6,12-14]. Ressalta-se, ainda, que a reutilização desses abundantes resíduos pelo setor de revestimentos cerâmicos pode contribuir de forma muito positiva para o desenvolvimento sócio-econômico e ambiental do país.

Neste contexto, o objetivo principal deste trabalho é estudar a influência da incorporação do resíduo de rocha ornamental, proveniente do setor de rochas ornamentais do estado do Rio de Janeiro, nas propriedades tecnológicas e microestrutura de piso cerâmico vitrificado.

\section{MATERIAIS E MÉTODOS}

Foram formuladas quatro composições de piso cerâmico
(Tabela I) com misturas de caulim, feldspato sódico, quartzo e resíduo de rocha ornamental. A massa cerâmica isenta de resíduo (formulação MR) é considerada a amostra de referência. $\mathrm{O}$ resíduo de rocha ornamental foi gradualmente incorporado até $30 \%$ em peso em substituição do feldspato sódico natural. O resíduo foi coletado numa empresa de corte de rochas ornamentais localizada no noroeste do estado do Rio de Janeiro. Além disso foram utilizados caulim, feldspato sódico e quartzo comercial. A Tabela II apresenta a composição química e a mineralógica das matérias-primas utilizadas.

As matérias-primas foram moídas a seco, separadamente, em um moinho de bolas de laboratório, até que as matériasprimas atingissem granulometria de $<325$ mesh $(45 \mu \mathrm{m}$ ABNT). Em seguida foram pesadas nas proporções de acordo com Tabela I e submetidas a mistura/homogeneização e granulação (processo via seca). O conteúdo de umidade das massas cerâmicas foi ajustado para $7 \%$ em peso de água. As massas cerâmicas foram mantidas em sacos plásticos fechados em dessecador por 24 h. As massas cerâmicas foram caracterizadas em termos de distribuição de tamanho de grânulos, morfologia, índice de plasticidade, massa específica real dos grãos, massa específica aparente, massa específica vibrada, índice de Hausner e resíduo em peneira $(63 \mu \mathrm{m})$.

As massas cerâmicas foram compactadas por prensagem uniaxial com ação única do pistão superior a $50 \mathrm{MPa}$, em uma matriz de aço de cavidade retangular (11,50 x 2,54 $\mathrm{cm}^{2}$ ). As peças cerâmicas compactadas foram submetidas a secagem em estufa a $110{ }^{\circ} \mathrm{C}$ por $24 \mathrm{~h}$. O processo de sinterização das peças cerâmicas secas foi em um forno de queima rápida (Maitec FSQC-1300/3). As temperaturas de patamar foram $1190,1210,1230$ e $1250{ }^{\circ} \mathrm{C}$. Foi empregado um ciclo de queima rápida de aproximadamente $60 \mathrm{~min}$.

As seguintes propriedades tecnológicas das peças sinterizadas foram determinadas de acordo com procedimentos padronizados: retração linear, absorção de água, massa específica aparente e tensão de ruptura a flexão (carregamento em três pontos). A análise qualitativa das fases cristalinas das peças sinterizadas foi feita por difração de raios X (Shimadzu XRD-700) com radiação $\mathrm{Cu}-\mathrm{k} \alpha$ e velocidade de varredura de $1,5^{\circ}(2 \theta) /$ min. A análise microestrutural da superfície de fratura das peças sinterizadas foi feita por microscopia eletrônica de varredura (Shimadzu SSX-550) via imagens de elétrons secundários em $15 \mathrm{kV}$.

Tabela I - Composição das massas cerâmicas (\% em peso). [Table I - Composition of the ceramic pastes (wt.\%).]

\begin{tabular}{ccccc}
\hline \multirow{2}{*}{ Matérias-primas } & \multicolumn{4}{c}{ Massas cerâmicas } \\
\cline { 2 - 5 } & MR & M10 & M20 & M30 \\
\hline Caulim & 40,0 & 40,0 & 40,0 & 40,0 \\
Quartzo & 12,5 & 12,5 & 12,5 & 12,5 \\
Feldspato sódico & 47,5 & 37,5 & 27,5 & 17,5 \\
Resíduo & 0,0 & 10,0 & 20,0 & 30,0 \\
\hline
\end{tabular}


Tabela II - Composições química (\% em peso) e mineralógica das matérias-primas. [Table II - Chemical (wt.\%) and mineralogical compositions of the raw materials.].

\begin{tabular}{ccccc}
\hline Compostos & Caulim & Quartzo & Feldspato sódico & Resíduo \\
\hline $\mathrm{SiO}_{2}$ & 49,70 & 98,97 & 69,55 & 66,43 \\
$\mathrm{Al}_{2} \mathrm{O}_{3}$ & 33,74 & 0,41 & 18,82 & 17,49 \\
$\mathrm{Fe}_{2} \mathrm{O}_{3}$ & 0,22 & $<0,01$ & 0,14 & 3,80 \\
$\mathrm{TiO}_{2}$ & $<0,01$ & 0,02 & 0,02 & 0,83 \\
$\mathrm{CaO}$ & 0,30 & $<0,01$ & 0,17 & 2,23 \\
$\mathrm{MgO}$ & 0,06 & $<0,01$ & 0,09 & - \\
$\mathrm{K}_{2} \mathrm{O}$ & 1,97 & 0,18 & 1,47 & 8,50 \\
$\mathrm{Na} 2$ & 0,52 & 0,13 & 9,63 & - \\
$\mathrm{MnO}$ & - & - & - & 0,07 \\
Perda ao fogo & 14,01 & 0,26 & 0,32 & 0,65 \\
Fases Cristalinas & Caulinita, & Quartzo & Feldspato sódico, & Feldspato \\
& quartzo e mica/ & & quartzo & potássico, \\
& illita & & & feldspato sódico, \\
& & & & quartzo, mica, \\
& & & & \\
& & & &
\end{tabular}

\section{RESULTADOS E DISCUSSÃO}

A distribuição de tamanho de grânulos para as massas cerâmicas após processo de granulação via seca é apresentada na Fig. 1. A incorporação do resíduo de rocha ornamental resultou em pequenas mas importantes modificações no comportamento granulométrico. Verifica-se que na massa cerâmica MR (massa cerâmica isenta de resíduo) a maior concentração dos grânulos encontra-se na faixa de tamanho 105-150 um. Por outro lado, nas massas cerâmicas contendo resíduo (M10, M20 e M30), a maior concentração dos grânulos encontra-se na faixa 150-250 $\mu \mathrm{m}$. No entanto, todas as massas cerâmicas estão dentro da faixa de tamanho de grânulos intermediária adequada para se obter boa reatividade durante o processo de sinterização [15]. Na Fig. 2 é apresentada a morfologia do pó granulado (formulação

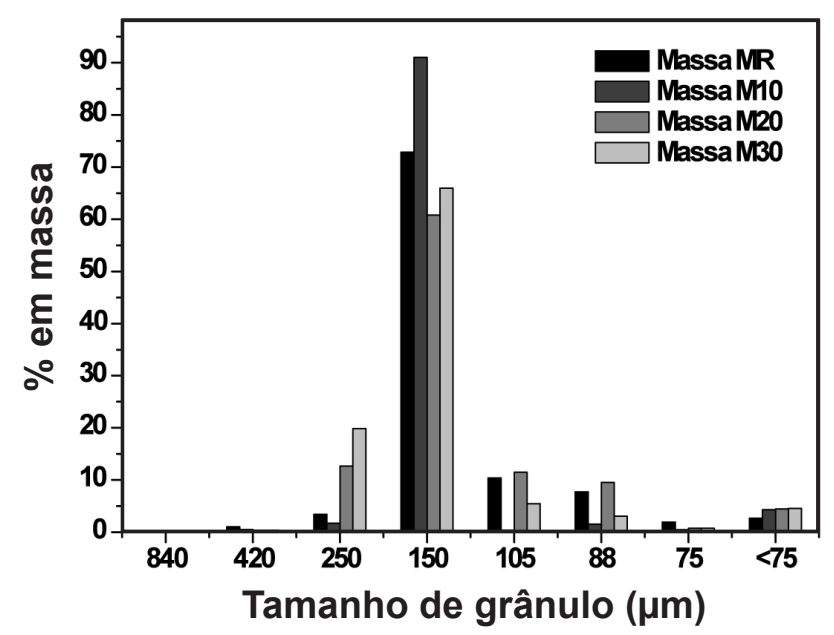

Figura 1: Distribuição de tamanho de grânulos das massas cerâmicas preparadas pelo processo via seca.

[Figure 1: Granule-size distribution of the ceramic pastes prepared by the dry process.]

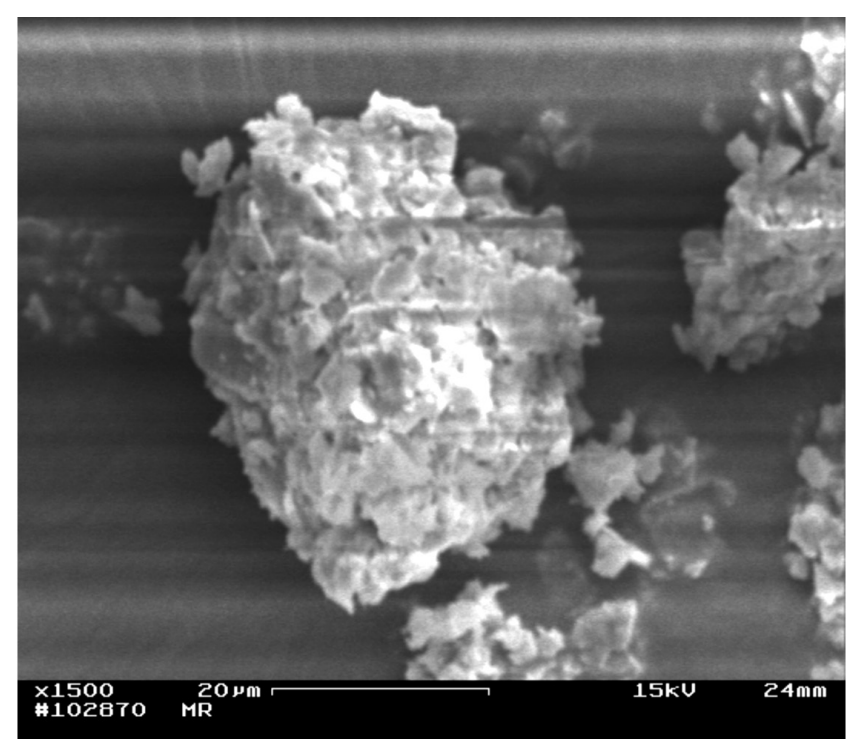

Figura 2: Morfologia das partículas do pó granulado.

[Figure 2: Morphology of the granulated powder.]

MR) obtida via microscopia eletrônica de varredura. Os grânulos apresentam morfologia irregular, que é típica de pós obtidos via granulação a seco. Esta morfologia foi obtida para todas as massas cerâmicas preparadas.

A Tabela III apresenta importantes características físicas das massas cerâmicas estudadas, como índice de plasticidade (IP), massa específica real dos grãos (MER), massa específica aparente do pó granulado (MEAG), massa específica vibrada do pó granulado (MEV), índice de Hausner (IH) e resíduo em peneira (RP). O resíduo de rocha ornamental provocou uma leve tendência de diminuição da plasticidade das massas cerâmicas. Isto se deve ao fato de que o resíduo contém certa quantidade de partículas de quartzo livre. No entanto, os valores obtidos de índice de plasticidade (14,3$15,5 \%)$ estão dentro da faixa adequada para produção de piso cerâmico vitrificado. Os valores de massa específica real das 
Tabela III - Características físicas das massas cerâmicas. [Table III - Physical characteristics of the ceramic pastes.].

\begin{tabular}{lcccccc}
\hline $\begin{array}{l}\text { Massa } \\
\text { Cerâmica }\end{array}$ & \multicolumn{6}{c}{ Características das massas cerâmicas granuladas } \\
\cline { 2 - 7 } & $\begin{array}{l}\text { IP } \\
(\%)\end{array}$ & $\begin{array}{c}\text { MER } \\
\left(\mathrm{g} / \mathrm{cm}^{3}\right)\end{array}$ & $\begin{array}{c}\text { MEAG } \\
\left(\mathrm{g} / \mathrm{cm}^{3}\right)\end{array}$ & $\begin{array}{c}\text { MEV } \\
\left(\mathrm{g} / \mathrm{cm}^{3}\right)\end{array}$ & IH & $\begin{array}{c}\text { RP } \\
(\%)\end{array}$ \\
\hline MR & 15,5 & 2,57 & 0,386 & 0,419 & 1,086 & 0,72 \\
M10 & 15,1 & 2,58 & 0,434 & 0,440 & 1,037 & 0,46 \\
M20 & 14,3 & 2,57 & 0,422 & 0,438 & 1,037 & 1,08 \\
M30 & 14,3 & 2,59 & 0,414 & 0,422 & 1,019 & 0,78 \\
\hline
\end{tabular}

partículas compreendidos entre 2,57 e $2,59 \mathrm{~g} / \mathrm{cm}^{3}$ refletem a composição mineralógica das massas cerâmicas. Em geral tem-se que a incorporação do resíduo aumenta o valor da massa específica real. Na Tabela III se observa também que os valores de MEAG e MEV das massas cerâmicas contendo resíduo são superiores àqueles da massa cerâmica MR. O índice de Hausner compreende a relação MEV/MEAG, o qual está relacionado à escoabilidade do pó granulado. Os resultados indicam que todas as massas cerâmicas apresentam valores de IH próximo de 1. Isto é indicativo que as massas cerâmicas estudadas, preparadas pelo processo via seca, apresentam boa fluidez. Os resultados também mostram que o efeito da substituição do feldspato sódico pelo resíduo de rocha ornamental foi o de diminuir o valor de IH. Isto provavelmente está relacionado a uma melhor distribuição de tamanho de grânulos para as massas contendo resíduo (Fig. 1). Na Tabela III são apresentados ainda os valores de resíduo em peneira de 250 mesh ( $63 \mu \mathrm{m}$ ABNT). Pode-se observar que as massas cerâmicas apresentaram baixo valor para o resíduo em peneira $(0,46-1,08 \%)$, o qual indica um bom nível de cominuição. Além disso, os valores obtidos estão dentro da faixa apropriada para fabricação de piso cerâmico vitrificado de alta qualidade [16].

Nas Figs. 3-6 são apresentados os diagramas de gresificação das massas cerâmicas. Estes diagramas são importantes para auxiliar na avaliação dos efeitos da incorporação do resíduo de rocha ornamental e da

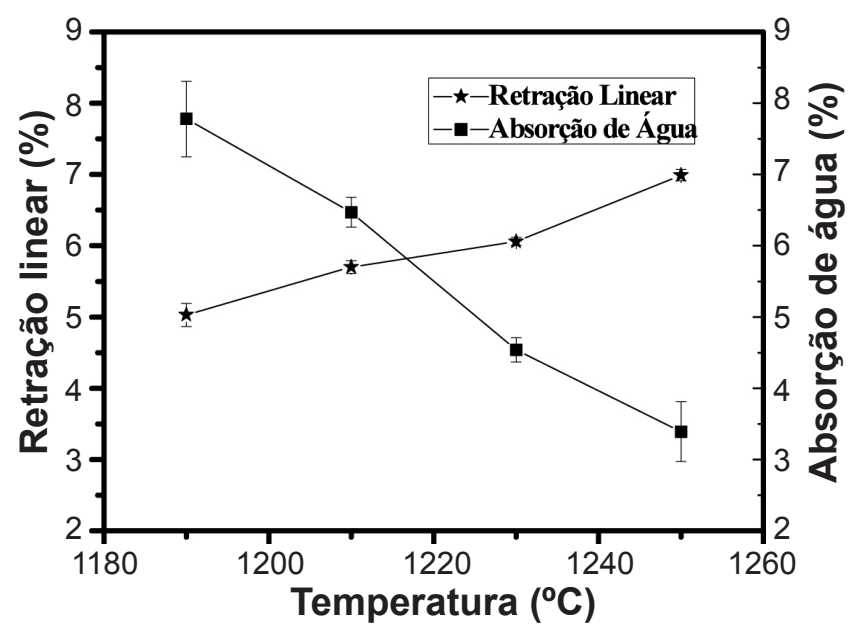

Figura 3: Diagrama de gresificação para a formulação MR. [Figure 3: Gresification diagram for the formulation MR.] temperatura de sinterização nas massas cerâmicas [17]. A substituição gradual de feldspato sódico pelo resíduo tende a modificar o comportamento dos diagramas de

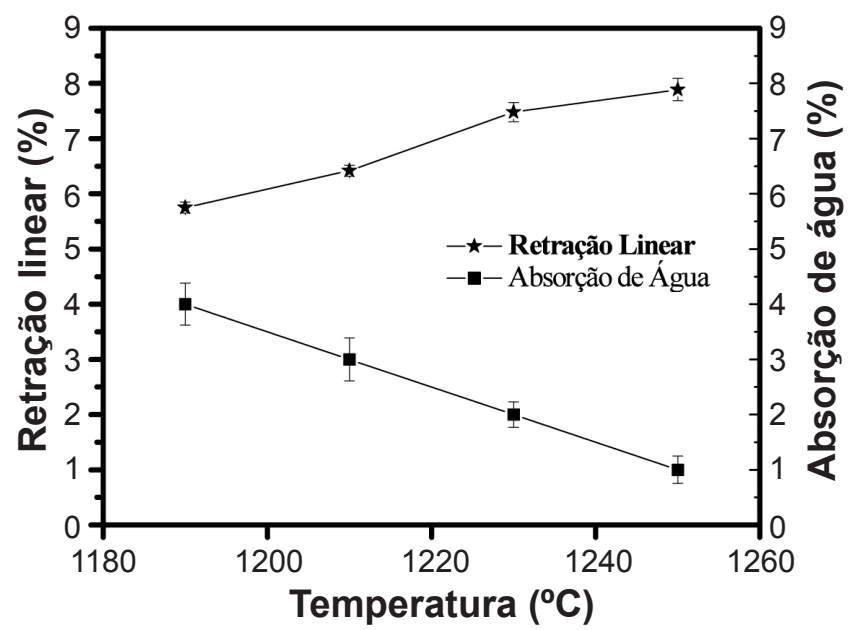

Figura 4: Diagrama de gresificação para a formulação M10. [Figure 4: Gresification diagram for the formulation M10.]

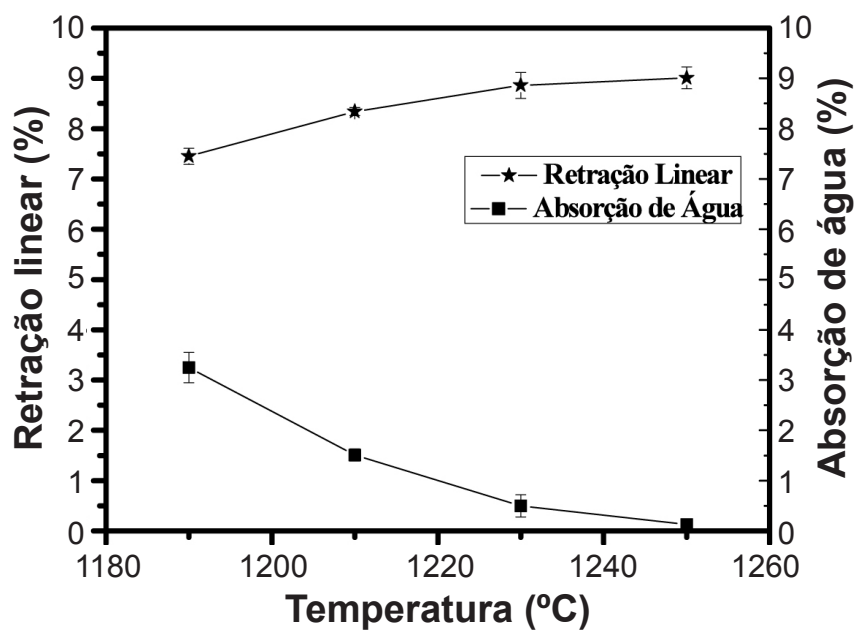

Figura 5: Diagrama de gresificação para a formulação M20. [Figure 5: Gresification diagram for the formulation M20.]

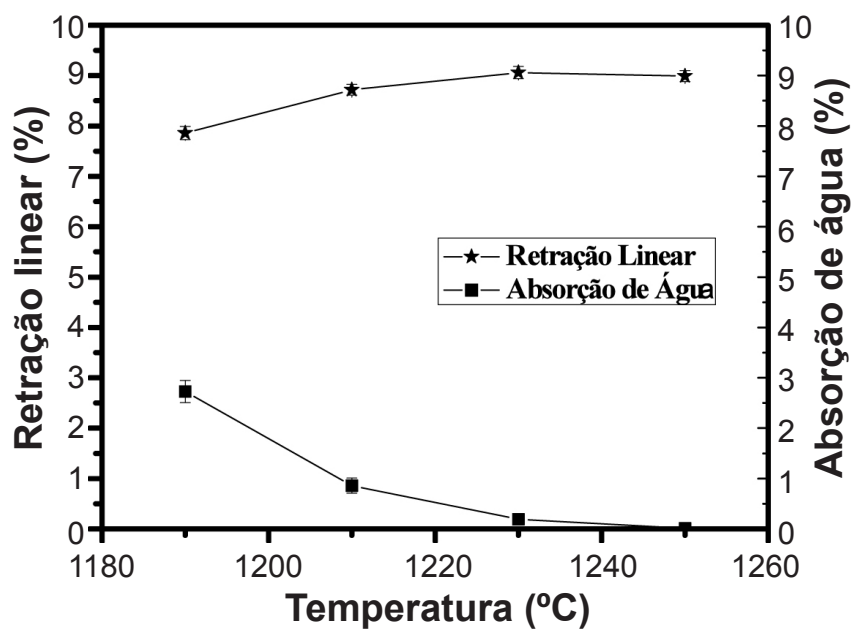

Figura 6: Diagrama de gresificação para a formulação M30. [Figure 6: Gresification diagram for the formulation M30.] 
gresificação. Em geral tem-se um aumento gradual da retração linear de queima (5,0 a 9,1\%) com concomitante redução dos valores de absorção de água (7,78 a 0,01\%). Isto se deve provavelmente a composição químicomineralógica do resíduo, que é rico em $\mathrm{K}_{2} \mathrm{O}$ e quantidades menores de $\mathrm{CaO}$ e $\mathrm{Fe}_{2} \mathrm{O}_{3}$. De forma que a incorporação do resíduo pode levar a formação de uma maior quantidade de fase líquida em menor temperatura de sinterização e menor viscosidade [6]. Os resultados também mostram que o efeito da temperatura de sinterização foi o de aumentar o grau de sinterização das peças cerâmicas. Em particular, o efeito da temperatura de sinterização foi o de reduzir fortemente a absorção de água (porosidade aberta) das peças cerâmicas. Isto ocorreu devido à formação de grande quantidade de fase líquida, que tende a permear e preencher os poros abertos da estrutura das peças cerâmicas por meio de forças de capilaridade. Após resfriamento a fase líquida se transforma em vidro. Verifica-se também que a adição do resíduo de rocha ornamental permite obter pisos cerâmicos de maior qualidade, como por exemplo, grês porcelanato (AA $<0,5 \%$ - ISO 13006), em temperaturas mais baixas. Isto é de alta importância tanto do ponto de vista econômico, quanto ambiental.

Na Fig. 7 estão apresentados os valores de massa específica aparente das peças cerâmicas. O processo de densificação em piso cerâmico vitrificado ocorre via sinterização por fase líquida. A taxa de densificação é controlada pela viscosidade e tensão superficial da fase vítrea [18]. A incorporação do resíduo acarreta modificações significativas $\left(2,51-2,45 \mathrm{~g} / \mathrm{cm}^{3}\right)$ na densificação das peças cerâmicas. Em geral as peças contendo resíduo são mais densas em todas as temperaturas de sinterização empregadas. Pode-se observar também na Fig. 7 que as peças preparadas com a formulação M30 sinterizadas acima de $1230{ }^{\circ} \mathrm{C}$ apresentam uma tendência de diminuição da massa específica aparente. Isto se deve a expansão do volume (inchamento) das peças cerâmicas devido a gás aprisionado na fase vítrea.

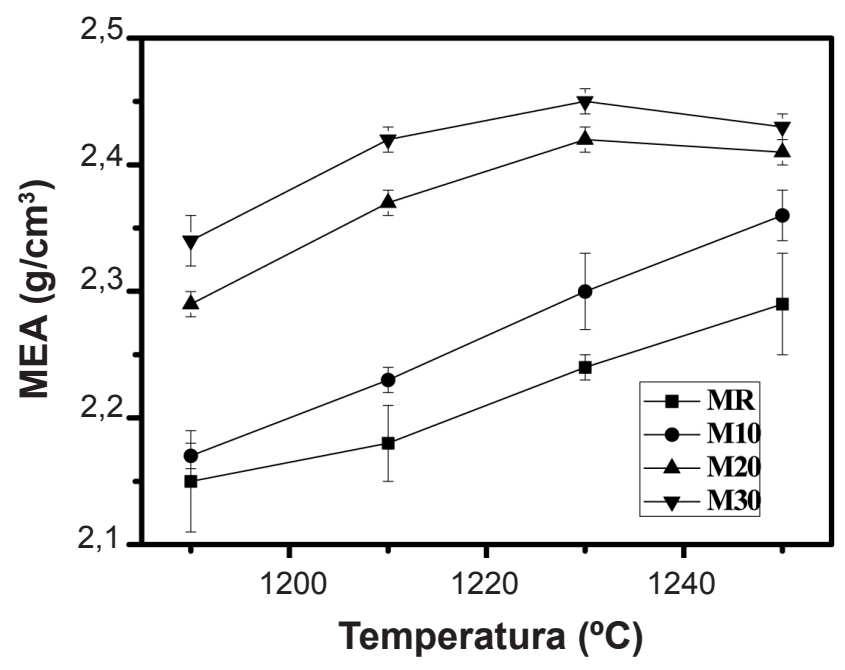

Figura 7: Massa específica aparente das massas cerâmicas. [Figure 7: Apparent density of the ceramic pastes.].
Na Fig. 8 é apresentado o comportamento da tensão de ruptura a flexão das peças cerâmicas. O efeito da incorporação do resíduo de rocha ornamental foi o de aumentar o valor da resistência mecânica $(29,42-60,51$ $\mathrm{MPa}$ ) das peças cerâmicas. Este comportamento era esperado uma vez que a incorporação do resíduo resulta em peças cerâmicas com maior grau de densificação.

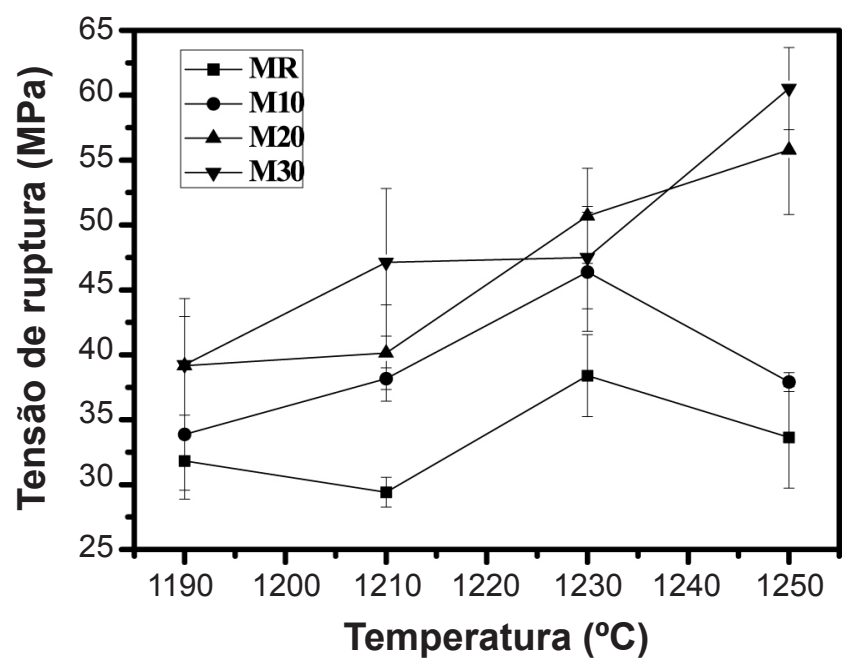

Figura 8: Tensão de ruptura a flexão das massas cerâmicas. [Figure 8: Flexural strength of the ceramic pastes.]

A Fig. 9 mostra os difratogramas de raios $X$ para a formulação MR (massa cerâmica isenta de resíduo) sinterizada em diferentes temperaturas. As peças cerâ-micas experimentaram uma série de reações e transformações de fase durante o processo de sinterização usando-se ciclo de queima rápido $[19,20]$. As fases cristalinas identificadas em todas as temperaturas de sinterização empregadas foram basicamente quartzo e mulita primária $\left(3 \mathrm{Al}_{2} \mathrm{O}_{3} \cdot 2 \mathrm{SiO}_{2}\right)$. Por outro lado já se observa também picos característicos de cristobalita.

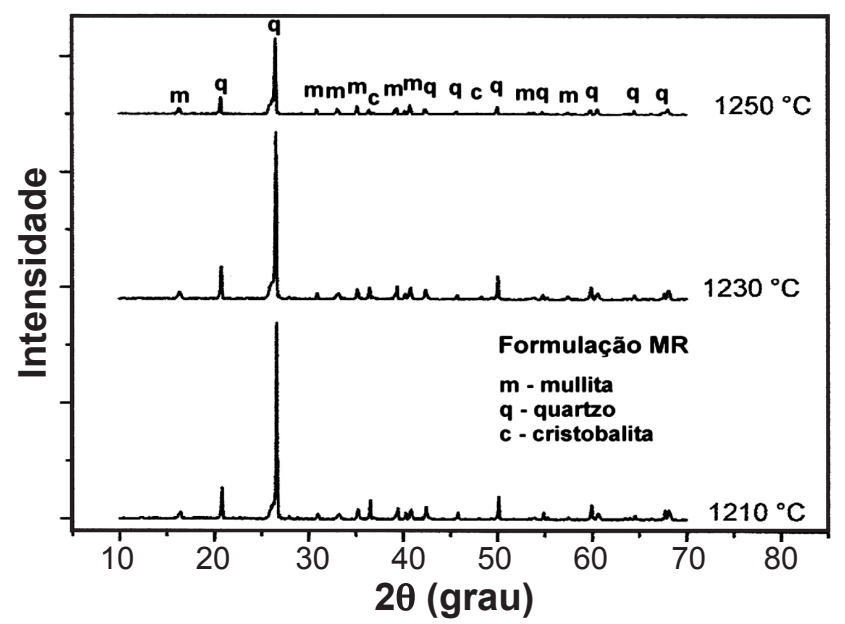

Figura 9: Difratogramas de raios $\mathrm{X}$ da formulação $\mathrm{MR}$ em diferentes temperaturas.

[Figure 9: X-ray diffraction patterns of the formulation MR at different temperatures.] 
Ainda, os picos de quartzo tendem a diminuir de intensidade com o aumento da temperatura de sinterização. Isto se deve à dissolução parcial das partículas de quartzo na fase líquida viscosa formada em alta temperatura. $\mathrm{Na}$ Fig. 10, estão apresentados os difratogramas de raios X da formulação M20 (com 20\% em peso de resíduo) sinterizada em diferentes temperaturas. As fases cristalinas são basicamente as mesmas observadas na formulação

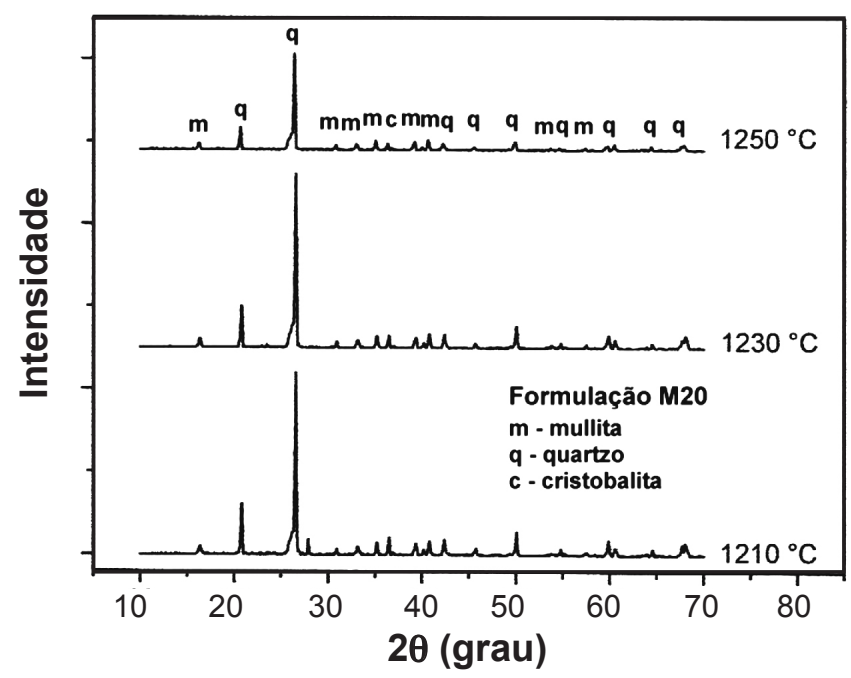

Figura 10: Difratogramas de raios $\mathrm{X}$ da formulação M20 em diferentes temperaturas.

[Figure 10: X-ray diffraction patterns of the formulation M20 at different temperatures.]
MR (Fig. 9), que são quartzo residual das composições de partida e mulita primária formada durante sinterização. Essas fases cristalinas podem ser previstas nos diagramas de equilíbrio de fases dos sistemas $\mathrm{Al}_{2} \mathrm{O}_{3}-\mathrm{SiO}_{2}-\mathrm{K}_{2} \mathrm{O}$ e $\mathrm{Al}_{2} \mathrm{O}_{3}-\mathrm{SiO}_{2}-\mathrm{Na}_{2} \mathrm{O}[6,21]$.

As Figs. 11a-c apresentam as micrografias da superfície de fratura obtidas por microscopia eletrônica de varredura da formulação MR em diferentes temperaturas. Pode-se observar a sequiência típica de densificação das peças cerâmicas com o aumento da temperatura de sinterização. Como esperado, a microestrutura consiste basicamente de partículas de quartzo e mulita primária (Fig. 9) embebidos na matriz vítrea. A $1210^{\circ} \mathrm{C}$ (Fig. 11a) a microestrutura é caracterizada principalmente por zonas rugosas com quantidade apreciável de pequenos poros abertos conectados com zonas densas (fase vítrea). Isto é característico de um processo de densificação incompleto. A $1230{ }^{\circ} \mathrm{C}$ (Fig. 11b) e $1250{ }^{\circ} \mathrm{C}$ (Fig. 11c) ocorreu uma redução das zonas rugosas e porosas com concomitante aumento das zonas densas. Em particular a $1250{ }^{\circ} \mathrm{C}$ temse uma estrutura já bem densificada. Nas Figs. 12a-c são apresentadas as micrografias da superfície de fratura das peças obtidas com a formulação M20. Nota-se que o efeito da incorporação do resíduo, em todas as temperaturas de sinterização, foi o de resultar numa microestrutura com textura mais suave e notadamente mais densa. Este resultado corrobora as propriedades tecnológicas (Figs. 3-8) das peças cerâmicas sinterizadas sob condições de queima rápida.
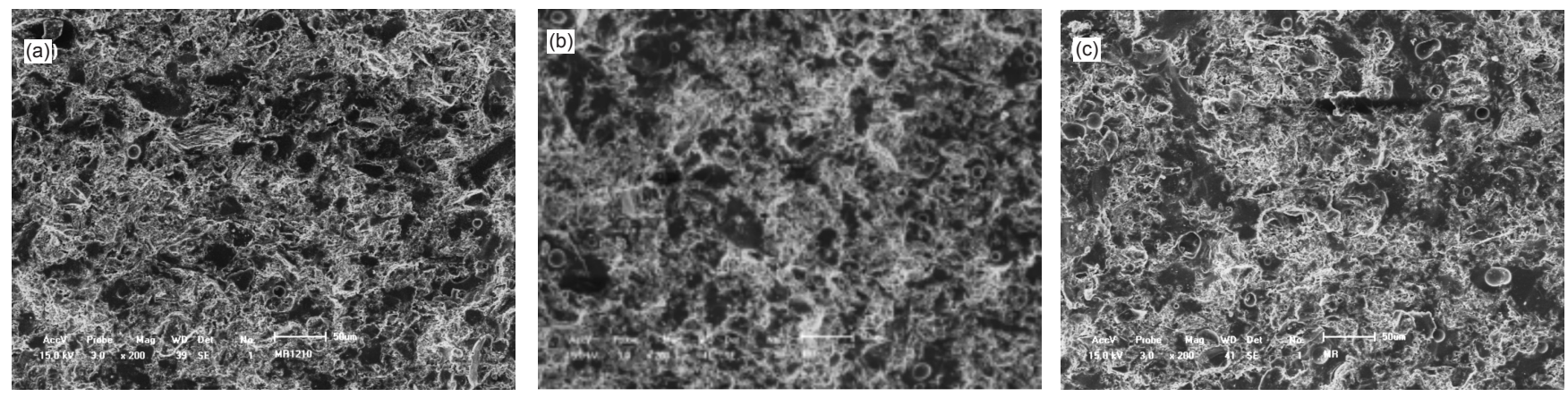

Figura 11: Micrografias (MEV) da formulação MR sinterizada: a) $1210^{\circ} \mathrm{C}$, b) $1230{ }^{\circ} \mathrm{C}$, e c) $1250{ }^{\circ} \mathrm{C}$. [Figure 11: SEM micrographs of the sintered formulation MR: a) $\left.1210^{\circ} \mathrm{C}, b\right) 1230^{\circ} \mathrm{C}$, and c) $1250{ }^{\circ} \mathrm{C}$.]
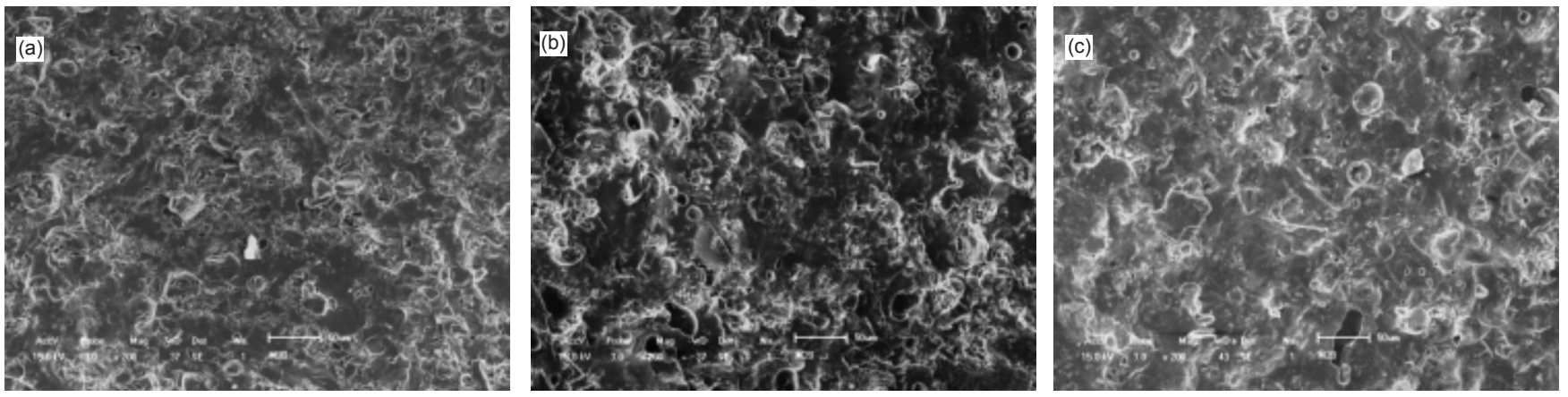

Figura 12: Micrografias (MEV) da formulação M20 sinterizada: a) $1210^{\circ} \mathrm{C}$, b) $1230{ }^{\circ} \mathrm{C}$, e c) $1250{ }^{\circ} \mathrm{C}$. [Figure 12: SEM micrographs of the sintered formulation M20: a) $\left.1210^{\circ} \mathrm{C}, \mathrm{b}\right) 1230^{\circ} \mathrm{C}$, and c) $1250^{\circ} \mathrm{C}$.] 


\section{CONCLUSÕES}

Os resultados experimentais obtidos indicam que o resíduo de rocha ornamental estudado pode ser incorporado como uma matéria-prima alternativa de baixo custo, em substituição do feldspato sódico (fundente natural), na formulação de massas cerâmicas para fabricação de piso cerâmico vitrificado de alta qualidade. $O$ efeito da incorporação do resíduo foi o de contribuir para um maior grau de vitrificação das peças cerâmicas. As peças contendo resíduo apresentam uma microestrutura mais densa com textura suave (menos porosidade aberta) e propriedades tecnológicas melhoradas. No entanto, a incorporação do resíduo de rocha ornamental estudado não modificou a evolução das fases cristalinas presentes nas peças cerâmicas sinterizadas.

\section{AGRADECIMENTOS}

Ao CNPq pelo apoio financeiro.

\section{REFERÊNCIAS}

[1] A. J. Souza, Diss. Mestrado, Universidade Estadual do Norte Fluminense Darcy Ribeiro, Campos dos Goytacazes, RJ (2008).

[2] R. R. Menezes, H. S. Ferreira, G. A. Neves, H. C. Ferreira, Cerâmica 48, 306 (2002) 92-101.

[3] J. P. V. T. Manhães, J. N. F. Holanda, Quim. Nova 31, 6 (2008) 1301-1304.

[4] H. F. M. Filho, H. Polivanov, E. V. Barroso, C. G. Mothé, Thermochim. Acta 392-393 (2002) 47-50.

[5] P. Torres, H. R. Fernandes, S. Agathopoulus, D. U. Tulyaganov, J. M. F. Ferreira, J. Eur. Ceram. Soc. 24 (2004)
3177-3185.

[6] A. M. Segadães, Adv. Appl. Ceram. 105 (2006) 46-54.

[7] Technical Report, Ind. Ceram. 27 (2007) 252-253.

[8] W. Worral, Ceramic Raw Material, Pergamon Pres., $2^{\text {nd }}$ Ed. (1982).

[9] E. Sánchez, Ceram. Ind. 8 (2003) 7-16.

[10] A. M. Rodriguez, S. A. Pianaro, E. A. T. Berg, A. H. Santos, Ceram. Ind. 9 (2004) 33-38.

[11] S. K. Das, K. Dana, Thermochim. Acta 406 (2003) 199206.

[12] M. S. Hernández-Crespo, J. Ma. Rincón, Ceram. Int. 27 (2001) 713-720.

[13] W. Acchar, F. A. Vieira, D. Hortza, Mater. Sci. Eng. A 419 (2006) 306-309.

[14] P. Torres, R. S. Manjate, S. Quaresma, H. R. Fernandes, J. M. F. Ferreira, J. Eur. Ceram. Soc. 27 (2007) 4649-4655.

[15] G. Nassetti, C. Palmanari, Ceram. Eng. Sci. Proc. 14 (1993) 15-24.

[16] A. P. N. Oliveira, Ceram. Ind. 5, 6 (2000) 37-47.

[17] F. G. Melchiades, E. Quinteiro, A. O. Boschi, Ceram. Ind. 1, 04-05 (1996) 30-31.

[18] M. Dondi, M. Raimondo, C. Zanelli, P. M. Tenório Cavalcante, Proc. Int. Conf. Sci. Technol. Appl. Sintering, Pennsylvania, EUA (2003).

[19] P. S. Santos, Ciência e Tecnologia das Argilas, 2a Ed., Vol. 1, Edgard Blücher Ltda, S. Paulo, SP (1989).

[20] A. Barba, V. Béltran, C. Felíu, J. Garcia, F. Ginés, E. Sánchez, V. Sanz, Materias Primas para la fabricación de soportes de baldosas cerámicas, $2^{\mathrm{a}}$ Ed., ITC, Castellón, Espanha (2002).

[21] E. M. Levin, C. R. Robbins, H. F. McMurdie, Phase Diagrams for Ceramists, Am. Ceram. Soc., Columbus, OH, EUA (1964).

(Rec. 19/11/2009, Ac. 28/05/2010) 